Gunawardana T.S.L.W., Wayamba Journal of Management 12 (1)

\title{
Effect of Computer-Mediated Communication System on Job Satisfaction of Employees in Transmission Division of Ceylon Electricity Board, Sri Lanka
}

\author{
T.S.L.W. Gunawardana \\ Senior Lecturer \\ Faculty of Management and Finance \\ University of Ruhuna. \\ SRI LANKA \\ gunawardana@badm.ruh.ac.lk
}

\begin{abstract}
This study aims to investigate how computer mediated communication (CMC) system have impacted on employee's job satisfaction of Ceylon Electricity Board, Sri Lanka to fill the gaps in the computer mediated communication literature and provide useful information on interpersonal relationships within an organization. The sample of the study consisted of 400 respondents representing executive and medium level technical service (MLTS) staff of the transmission division of Ceylon Electricity Board in Sri Lanka. Self-administered questionnaire and the web-based questionnaire was used to collect primary data while data were analyzed with Partial Least Squares path modeling (PLS). The research findings indicated that computerized maintenance management is the most significant factor impacting on the employees' job satisfaction and it also identified that there is a positive and statistically significant impact of instant messaging and electronic mails on employees' job satisfaction. The results provide valuable input regarding the instant messaging and job satisfaction.
\end{abstract}

Keywords:- Computer-mediated communication system, computerized maintenance management solution electronic mails, instant messaging, and job satisfaction

\section{INTRODUCTION}

With the development of technology the communication process and pattern in the workplace has been dramatically changed (Paraskeva, Eriksson, Johansson, \& Peter, 2019). Today technological innovations and internet are major aspects which have influenced the communication approaches in the organizations. Koschmann (2012) states that there is a rapid growth in the use of technology for communication every year and as well as the new advancements are made in the same frequency. 
Many organizations have begun to practice new communication technology in employee communication (Anton, 2012). Especially Computer-mediated communication (CMC) system has radically emerged and been introduced in many workplaces to make a significant shift towards technological adoption in their communication practices (Sayago, Sloan, \& Blat, 2011). In this era, computer-mediated communication is a basic infrastructure that every organization need to be equipped with.

The computer-mediated communication system has done significant changes in the ways people communicate and associate with each other in both government and private sector organizations today (Jayalal \& Balasuriya, 2015). With the use of CMC, system information can be sent to single as well as multiple recipients thus making the distribution of information easier and quicker than ever before (Wellman, Salaff, Dimitrova, \& Garton, 1996). Organizations believe that access to and use of this information would result in increased worker productivity and efficiency and make it easier for them to communicate with employees (Bob \& Sooknanan, 2014). With this rapid change in communication technology, the organizational culture and employees working environment, organizational language, interpersonal relationships of the employee has changed as a result of CMC effects. These changes which were created due to $\mathrm{CMC}$ system influence has made a significant impact on employees work life and their job satisfaction (Dhir, 2018). In line with the discussion, job satisfaction may be identified as a construct which is concerned with the psychological incidents at the workplace that adds greater linkage among employees, their jobs and their organization (Okwudili, 2012).

On the other hand, the employees should have up-to-date technological skills or have to develop those skills to adapt to the digitalizing work environment. Learning and adapting to new technologies may increase the workload and cause stress (Bordi, Heikkilä, \& Okkonen, 2014). The number of technologies used at work, constant changes in ICTs, plus malfunctions and usability problems of the systems may increase the risk of lowered wellbeing and satisfaction (Day, Scott, Kelloway, 2010). Thus, if the CMC system has an impact on job satisfaction, then organizations using CMC system have an effective tool for influencing employee job satisfaction. With technological advancements, most of the organizations get improved by adopting the latest components to their communication practices(Lee, 2011). 
Most of the researches (Belle, Hall, Riekert, \& Muganda, 2007; Lau, 2014; Bob \& Sooknanan, 2014) have conducted researches on the topic of impact of computer-mediated communication on the interpersonal relationship of couples, groups or workers. Nevertheless, every organization not only in western countries all over the world are using the $\mathrm{CMC}$ system as their main communication media, there are only a few studies done on workers performance or employee satisfaction in the CMC environment. However, most of the CMC studies focus on the CMC effect, use and user satisfaction. According to the literature found (Epure, Ionescu, \& Nancu, 2013; Giri, \& Kumar, 2010; Mukahi, Nakamura, \& Not, 2003) there are very few numbers of research were done in the world to examine the impact of $\mathrm{CMC}$ on job satisfaction.

In the Sri Lankan context, research to find the direct impact of the CMC system on and job satisfaction in the service sector of Sri Lanka is still not done. So, there is a problem of whether the CMC practices can improve the job satisfaction of employees. Therefore, this research study is most important to fill up that research gap identified in the Sri Lankan context.

Ceylon Electricity Board (CEB) is a large scale organization distributed its branches to every nook of the country to supply energy to all categories of power consumers and sale of electrical energy in islandwide. CEB also has been adopted $\mathrm{CMC}$ technology to the organizational communication and other related tasks for last decay. Due to the advancement of this technology, there is an increasing number of workplace activities involve computer-mediated

communication (CMC) system and $\mathrm{CMC}$ system has changed the ways of people communicate and relationships in each other in an organization. The research question, therefore, leading directly to an empirical investigation in this study is "Does the adaptation of computer-mediated communication (CMC) system lead job satisfaction of the employees in Ceylon Electricity Board, Sri Lanka?"

\section{LITERATURE REVIEW}

\subsection{Traditional Communication to Modern Communication}

Bordi, Tammi, \& Okkonen (2014) reveals that computermediated communication and electronic documents are mostly favored over traditional telephone calls and paper, as they seem to be easier to manage and increase the opportunity of having further control over employee's work. Before the $70^{\text {th }}$ decade, some people thought using computers for information exchange as dangerous. Some people feel threatened by computers (Dahanayake, 2015). But 
after1970s, some people start to feel computers enhance their opportunities of making any information available to someone and supporting information exchange easily and speedily irrespective of geographical distances (Palme, 2000).

With the development of computer and internet technology, computer-mediated communication (CMC) appropriated all forms of communication facilities in the workplace. CMC improved vertical and horizontal information flow more efficiently across organizations as well as information intake to the organization. Not only the fastness of CMC practice but also volume and portion in the organizational work done are getting greater and greater rapidly. As a result of factors such as greater access to organizational power, decisionmaking and creative processes it has also been credited with significant improvement in task efficiency, planning, promoting timely and complete feedback, controlling organizational activities, managing time, initiating action plans, responding to the environment, planning flexible work schedule (Bob \& Sooknanan, 2014).

\subsection{Computer-Mediated Communication (CMC)}

Different authors have different approaches to defining computermediated communication.
According to Kim (2002), computer-mediated communication is defined as an interpersonal or group level communication which is mediated by a computer, but mass communication is eliminating here. December (1997) defined that "a process of human communication via computers, involving people, situated in particular contexts, engaging in processes to shape media for a variety of purposes" (p.3), while based on the definition of Stasser (1992) CMC can be defined as a process of negotiating the meaning of various situations arises between the group of social actors. As claims of Metz (1992) computermediated communication (CMC) is described as any communication patterns mediated through the computer.

There are lots of advantages that employees can enjoy because of the CMC systems introduced and developed in an organization. As claims of Rowley(1999), CMC makes the response more quickly than was possible through a letter or memo as well as can attach more files and communicate with groups on one occasion. So, CMC creates faster, speeder and reliable communication service. Further, he discussed the management and development of organizations considered to be centralized with CMC, and, indeed, the style of communication can influence interpersonal relationships, and in turn, factors such as commitment 
and motivation. Gush (1999) researched to examine the potential and limitations of computer-mediated

communication (CMC) in an educational context at Bournemouth University on two courses to serve the needs of students out on their work placement year. There he found that the CMC is its ability to facilitate learning at a distance by providing a sophisticated tool for communication. The advantage of this is, therefore it creates new knowledge and understanding while working collaboratively with a view and can deliver against desired outcomes (Bordi, Tammi, \& Okkonen, 2014).

\subsection{Dimensions of CMC}

Since computer-mediated communication is rapidly developing technology its dimensions vary with time. The various researches describe CMC system with various models. According to Harold Dwight Lasswell's ' $5 \mathrm{~W}$ ' theory, the CMC system is a new form of communication with its own five characteristics Subject, Host, Information resource, Channel, Relations and Effects. Further, researcher Yu (2011) identifies CMC system composed of human and computers, absorbs and then extends the advantages of all former formats of communication, acceptance the instant interaction of oral communication, the intellectual logics of printing dissemination, and the vivid images of movie and television.

The researcher Simpson, (2002) further describes that where interaction takes place in realtime synchronous CMC and where participants are not necessarily online simultaneously asynchronous CMC. Synchronous CMC includes various types of text-based online chat, computer, audio, and video conferencing; asynchronous CMC encompasses email, discussion forums, and mailing lists. Stefan (2008) has researched to explore formal and informal dimensions of CMC. In his paper, he has further developed Fish's (1990) model of distinguishes characteristics of informal and formal dimensions of computer-mediated communication (CMC). His findings revealed that a medium (Channel) may be more or less useful for supporting informal or formal communication.

According to Samarawickrama (2017), the usage of computerrelated communication has grown in government institutes of Sri Lanka began in 1960. With the establishment of Sri Lanka Telecom (SLT) in 1991 and the initiation of SLT Internet service facility in 1996 adaptation to $\mathrm{CMC}$ is increased in public and private sector organizations. Therefore, CMC systems and its dimensions such as instant messaging, email, chat rooms, online forums, and social network services start to play a major role 
in organizational communication in education, health, banking, travel \&Tourism and manufacturing industries in Sri Lanka. The commonly used CMC dimensions in Ceylon Electricity Board are discussed follows according to different views of different authors to set up the hypothesis.

\subsubsection{E-mails}

Electronic mail or e-mail is defined as the transmission of messages over communications networks. Those messages containing text, documents, sound, pictures, and even computer programs. Computers are generally used as terminals, but electronic agendas, cell phones, data communication terminals or other data exchange equipment can also be used to send emails (Beal, 2019). Currently, more than 600 million people around the world use email as a means of communication for personal and business communication needs (Mertena \& Gloorb, 2009). With the development of the World Wide Web, the email also continued to develop, with providers such as Hotmail, Yahoo, and Google offered free email accounts.

E-mail possess the highest level of social presence, followed by other CMC dimensions as claims of (Tu, 2002). He reveals also email is more public in public and private sector organizations today. Quaresma, da Silva, \& Marreiros, (2013) empirically studied the use of e-mail in an organizational context, using a sample of the Portuguese population with an active e-mail account assigned by the employer. The results show that most users have what is considered appropriate behavior. The paper of Smith \& Tabak, (2009) provides evidence of work outcomes of e-mail monitoring regarding employee attitudes and behaviors such as organizational commitment, job satisfaction, and performance. Not only the positive impact, but there are some drawbacks as well. Mertena \& Gloorb,(2009) calculated email responsiveness and conducted an individual job satisfaction survey. They identified patterns of productive and less-productive e-mail usage. Results indicate that central network position reduces e-mail responsiveness, while this position in the organization's social network also seems to be correlated with lower job satisfaction. The team which sent and received the most e-mail reported the lowest job satisfaction.

\subsubsection{Instant Messaging}

Instant messaging (IM), is the near real-time conversation in a private, back and forth style of communication of two users by exchanging messages through a stand-alone application or embedded software (Rouse, 2008). With the development of technology now it can be transferred not only text messages but also transfer files 
and images by using IM. To Larson, (2011)'s definition of Instant messaging (IM) technology is a type of online chat that offers real-time text transmission over the Internet. More advanced instant messaging can add file transfer, clickable hyperlinks, Voice over IP, or video chat. Instant messaging is gaining popularity in organizations because it speeds up the communication process. Cho, Trier, \& Kim, (2005) states that IM as a double-edged sword. Because when IM help to facilitate quality communication and trust, on the other hand, it interrupts the work. However, when the negative effects if IM is negligible. However, he further states that IM can usefully increase other CMC tools and create an effective and comprehensive CMC environment in the workplace therefore it leads to better work performance of employees. Another research has done by Sias, Pedersen, Gallagher, \& Kopaneva, (2012) to examine teleworkers' job satisfaction related to the use of and satisfaction with a variety of communication channels and he reveals that Teleconferencing and instant messaging ranked as least satisfying among a range of communication channels available to teleworkers.

\subsubsection{Computerized}

\section{Maintenance Management Systems (CMMS)}

A computerized maintenance management system (CMMS) is a software package designed to maintain a computer database for an organization's maintenance operations and human resources function (DeSanctis \& Poole, 1994). Computerize Maintenance Management system (CMMS) helps schedule all types of maintenance jobs such as maintenance operations, labor handling, purchasing and inventory handling and providing statistical reports. Each responsible employee for above activities can involve for their job simultaneously if they are geographically dispersed because of CMC. CMMS is leading CMC system in Sri Lanka for utility management. A Computerized Maintenance Management System (CMMS) is a computer software program designed to assist in the planning, management and administrative functions required for effective maintenance. According to the findings of Higgins, Brautigam, \& Mobley, (1995) that CMMS manage maintenance information contributes to improved communication and decisionmaking capabilities and improve the information and communication facilities of repair needs and work priorities. Further, they found in their research that CMMS has the capability of improving coordination through closer working relationships between maintenance and production. So it increased maintenance responsiveness of employees. 
Rastegari \& Mobin (2016) says that electronic communication between offices in an organization improve with CMMS because they can send work assignments to maintenance workforce through mobile devices and so they can operate more efficiently in the field, for timely completion of required maintenance and repairs. On top of that, CMMS lets your team communicate in a more efficient manner which means the work can be started faster and subsequently finished under set deadlines. To attain a better understanding of how advanced CMMS trigger satisfaction amid their resource (employees) hereby refer to Adaptive Structuration Theory (AST) to describe the process by which people incorporate advanced technologies into their work practices. Once applied, technologies should trigger a structural change in terms of productivity, efficiency, and satisfaction to individuals and organizations (DeSanctis \& Poole, 1994).

\subsection{Employees' Job Satisfaction}

Various researchers and practitioners have provided their definitions of what job satisfaction is. However, some of the most common definitions describe job satisfaction as a psychological, behavioural and occupational response by employees' towards fulfilment at their job. It is an expression of an employee of a particular segment of the work (For instance, reward, authority, peers). Kumar (2002) has defined the job satisfaction is a significant principle for the success of an organization where it is closely associated with life satisfaction. That means employees satisfaction is directly proportional to organizational performance. Therefore, employees can make or break an organization (Deal, 2007). Brief \& Weiss (2002) defined job satisfaction as "a pleasurable or positive emotional state resulting from the perception by the individual of his/her job as implementing or allowing realizing significant values available in the work, provided that these values are consistent with his/her needse (p.282). According to this definition that job satisfaction is the somewhat subjective person to person. Weiss, (2002) also defines the same concept of' job satisfaction represents a person's evaluation of his or her job and work context (pp. 173). Satisfaction depends on the level of discrepancy between people expect to receive and what they experience. Further Locke, (1976) defines job satisfaction as really a collection of attitudes about specific facets of the job. Employee satisfaction is equivalent to the expectations of the employee about the workplace and his attitudes towards his job. So, job satisfaction is also a moral obligation in many societies. Gradually it can conclude that job satisfaction is subjective, 'a happy worker is a productive worker. 
The importance of job satisfaction for any organization is huge as it is linked to many variables, including productivity, absenteeism, turnover, etc. It is significant because a person's attitude and beliefs may affect his or her behavior (Saleem, Majeed, Aziz, \& Usman, 2013). If the employees in an organization satisfied with their job it will lower turnover, higher productivity, increased customer satisfaction, employee absenteeism, helps to earn higher revenues, satisfied employees tend to handle pressure (Okwudili, 2012). Therefore if the company has satisfied employee base, that is the strength of the company. Perceived job satisfaction was measured by Epure, Ionescu, \& Nancu, (2013) using six dimensions, respectively named as working conditions, promotion opportunities, frequency of training, wage and compensations schemes, employee fluctuation and importance of work within the organization in there research study. As well as according to Multi-Motivation Theory (Murasugi and Miki 1990), which was developed in Japan based on Maslow's (1954) and Herzberg's (1968) work motivation theories, that employees are motivated by four factors. They are working conditions, interpersonal relations, satisfaction with job content, and company policy.
Communication, as well, was a subject of interest to many researchers who discussed its impact on employee's job satisfaction. The results of (Jacobs, Yuo, \& Chavez, January 2016) research revealed that internal communication has a significant positive effect on employee satisfaction. Based on Attar \& Sweis (2010) communication are the variables that most contributed to employee satisfaction within contracting firms. Effective communication in combination with satisfied employees. The satisfied employee is mandatory for improving the firm performance in the coordination of resources. According to Epure, Ionescu, \& Nancu, (2013) researched Romanian company's job satisfaction is strongly affected by communication: the more individuals communicate within companies, the more satisfied they feel with their job. Several types of research have empirically found that there was a positive relationship between effective communication and job satisfaction. According to Giri \& Kumar, (2010) identifies organizational communication had a significant effect on job satisfaction and job performance of the employees. The analysis further indicated that the employees at different levels perceived job satisfaction differently. Thus, it can be seen job satisfaction and performance are very much dependent on the communication behavior of the organization. 


\section{METHODS}

\subsection{Conceptual Framework and Hypotheses}

As Points outs by (Balouch \& Hassan, 2014) modern management science's philosophy considers job satisfaction as a baseline standard of satisfaction reported by many different characteristics of work and the workplace. There are various features of the work and the workplace that valued to job satisfaction. Researchers have attempted to explain the effects of CMC using different theories. From media richness theory Daft \& Lengel, (1986) suggests that email is a leaner medium due to the text-based and asynchronous nature of e-mail. The impact of communication channel satisfaction, personality, and job satisfaction could be explored from a social influence perspective (Fulk, Schmitz, and Steinfield, 1990), or a media richness perspective to better predict how each variable will influence job satisfaction of teleworking employees (Waldeck, Seibold, \& Flanagin, 2004). The other study by Cameron \& Webster (2005) used the media richness theory to investigate why employees use IM at work. To attain a better understanding of how advanced CMMS trigger satisfaction amid their resource (employees) hereby refer to Adaptive Structuration Theory (AST) to describe the process by which people incorporate advanced technologies into their work practices (Gopal, Bostrom \& Chin, 1993). Once applied, technologies should trigger a structural change in terms of productivity, efficiency, and satisfaction to individuals and organizations (DeSanctis \& Poole, 1994). Therefore, the present study developed the conceptual framework (figure 1) to investigate the impact of email, instant messaging and CMMS in the workplace and its correlation with two core concepts of media choice theories: media richness, social influence, and adaptive structuration theory (AST).

\subsubsection{Electronic Mails and Job satisfaction}

Bob \& Sooknanan, (2014) and Urquhart, Bommelje, \& Schmid, (2002) found that there is a positive relationship between CMC dimension of email with job satisfaction. Based on the findings of Bob \& Sooknanan, (2014), it is evident that the majority of employees felt that email usage had increased productivity and efficiency in the workplace. Mukahi, Nakamura, \& Not, (2003) states that email usage is highly important for employees individually as well as for the performance of the organisation and those organizations managing $\mathrm{CMC}$ well. The findings of all these research show that electronic mail usage strongly affects an employee's job satisfaction. Based on the aforementioned arguments, the following hypothesis is formulated, 


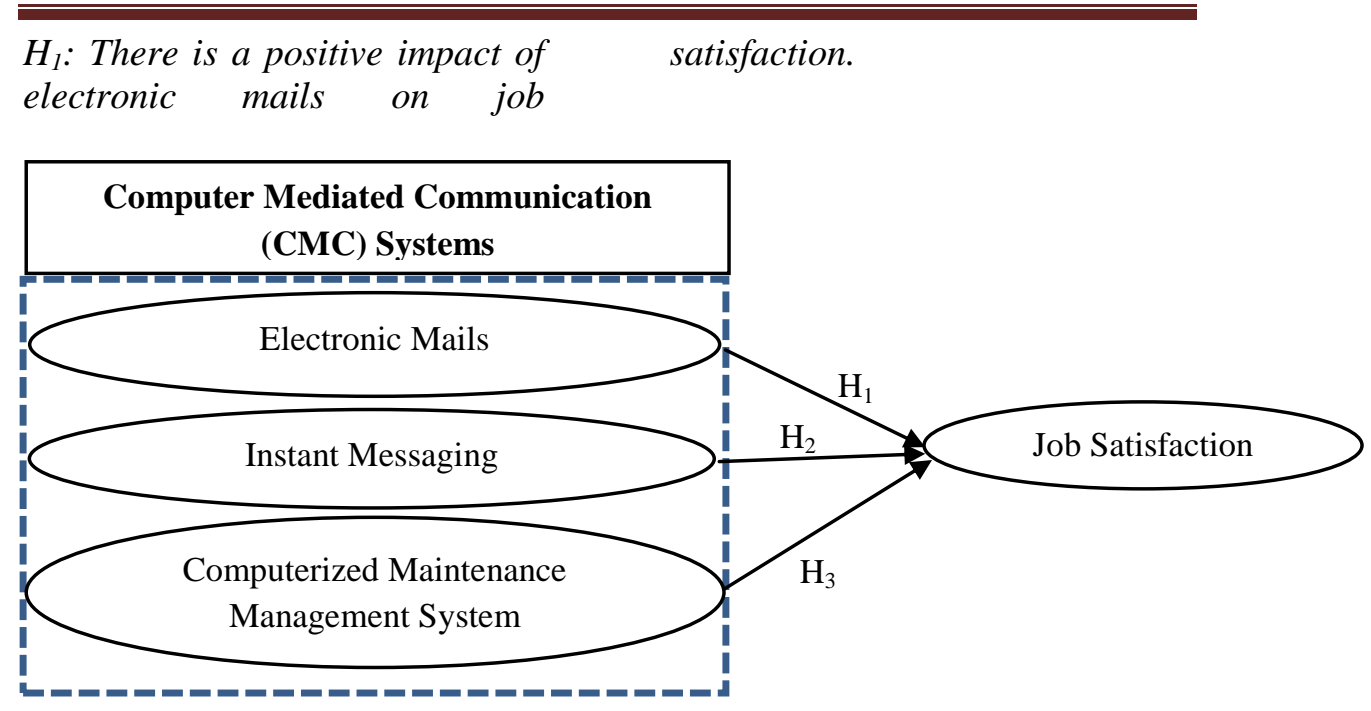

Figure 1: Conceptual Framework

\subsubsection{Instant Messaging and Job Satisfaction}

As claims of Iskandar, Arham, \& Shohaime, (2017) there is a significant relationship between the uses of instant messaging with performance. Instant messaging is one of the more prominent computer-mediated communications which can boost an instant reaction, similar to face to face communication $\mathrm{Ou}$, Sia, \& Hui, (2013) and Cameron \& Webster, (2005) described instant messaging allows employees to communicate in real-time and shows those who are online and currently available to receive messages. Lee, ( 2011) found in her research which has been conducted to understand the potential impact of using IM in the workplace, the position power of the IM jointly influence employee satisfaction and subjective task complexity. Based on the above discussion following hypothesis is proposed.

$H_{2:}$ There is a positive impact of instant messaging on job satisfaction.

\subsubsection{Computerized}

Maintenance Management

System (CMMS) and Job

\section{Satisfaction}

According to the findings of Higgins, Brautigam, \& Mobley, (1995) that CMMS manage maintenance information contributes to improved communication and decisionmaking capabilities and improve the information and communication facilities of repair needs and work priorities. Further, he found in his research that CMMS has the capability of improving coordination through closer working relationships between maintenance and production. So it increased 
maintenance responsiveness of employees. Rastegari \& Mobin, (2016) says that electronic communication between offices in an organization improve with CMMS because they can send work assignments to maintenance workforce through mobile devices and so they can operate more efficiently in the field, for timely completion of required maintenance and repairs. Even though prior empirical evidence on these relationships is less based upon the preceding discussion following hypothesis is proposed.

$\mathrm{H}_{3}$ : There is a positive impact of CMMS on job satisfaction.

\subsection{The Sample, Study Variables, Questionnaire Design and Data Collection}

Since Ceylon Electricity Board is multi-divisional organization spread over to every nook of the country, it is well recommended to do a descriptive cross-sectional research study to test the formulated hypothesis. The primary data was collected using a structured questionnaire and the secondary data was collected from previous research papers, the Internet and books. The researcher survey carried out with mixed-mode and it also included quantitative and qualitative questionnaires. Face to face interview would be helped to identify existing issues and base on that research has been created the questionnaire. The study selected executive and medium level technical service (MLTS) staff of the transmission division of CEB as the population of the study, while executive and medium level technical staff grade employees of Western and Southern provinces are the sample in this research. Simple random sampling method was applied to select the managerial level employee in the transmission division of CEB as a unit of this analysis. Out of 200 questionnaires delivered, 50 were delivered as a web-based questionnaire and the response rate was $50 \%$ and the remaining 150 questionnaires were distributed personally. However, 75 questionnaires were usable to the survey after the personal distribution as there were six incomplete questionnaires, while response rate was $54 \%$. As such, the total of 100 usable questionnaires was considered for the analysis with a $53 \%$ overall response rate. A structured questionnaire used in the study consisted of three parts including the first part for the demographic data of the respondents, the second part to elaborate the background information of the respondents, and the third part relates to the hypothesis of the study.

The four study constructs of the study i.e., electronic mails, instant messaging (IM), computerized maintenance management system (CMMS) and job satisfaction were operationalized as multi-item constructs. The seven items of the electronic mails were adopted from Bälter (1998); Iskandar, 
Arham, \& Shohaime, (2017); and Quaresma, Da Silva \& Marreiros (2013). Instant messaging consisted of seven items were adopted from Mahatanankoon (2010); Mukahi, Nakamura, \& Not (2003); Lee, (2011); and Iskandar, Arham, \& Shohaime, (2017), while computerized maintenance management system (CMMS) consisted of seven items adapted from Mukahi, Nakamura \& Not,(2003); and Chauhan \& Singh (2016). Job satisfaction consisted of 11 items adapted from Mukahi, Nakamura, $\&$ Not (2003).

\section{RESULTS}

Structural equation modelling (SEM) was used in this study to assess the predictive power of the theoretical model and testing the formulated hypothesis. Internal consistencies of the constructs were examined using the composite reliability index. Discriminant validity indicates the extent to which a given construct is different from other latent constructs. Fornel and Larcker (1981) have suggested using the average variance extracted (AVE) in evaluating the discriminant validity of constructs. Partial least square technique using Smart PLS version 20 was used to test the hypotheses, while SPSS software package was used to check frequency statistics of the demographic variable.

\section{Table 1: Discriminant Validity of the Latent Variables}

\begin{tabular}{|l|c|c|c|c|}
\hline & 1 & 2 & 3 & 4 \\
\hline Electronic mails & $\mathbf{0 . 8 6 5}$ & & & \\
\hline $\begin{array}{l}\text { Instant } \\
\text { Messaging }\end{array}$ & 0.209 & $\mathbf{0 . 8 7 3}$ & & \\
\hline CMMS & 0.438 & 0.007 & $\mathbf{0 . 9 1 3}$ & \\
\hline Job satisfaction & 0.587 & 0.232 & 0.619 & $\mathbf{0 . 9 1 2}$ \\
\hline
\end{tabular}

Source: Survey Data (2021)

Discriminate validity is the degree to which any single construct is different from the other constructs in the model (Carmines \& Zeller, 1979) and it is assessed by the test provide by Fornell and Larcker (1981) in which the pair-wise latent variable correlations between factors obtained are compared with the square root of the average variance extracted estimates for the constructs making up each possible pair as illustrates in table 1.

\subsection{PLS Path Model Estimation}

In Partial Least Squares (PLS) method, structural model and hypothesis were tested by computing path coefficients ( $\beta$ ). Because PLS does not require a normally distributed data it is evaluated with R-squared calculation for dependent latent variables (Cohen, 1988) and the average Variance extracted (Fornell \& Larchner, 1981) as 
shown in Table 2.

Table 2: Results of PLS Path Model Estimation

\begin{tabular}{|c|c|}
\hline & \multirow{2}{*}{$\frac{\text { Job Satisfaction }^{\text {a }}}{\text { Estimates (t-Value) }}$} \\
\hline & \\
\hline 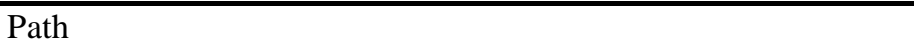 & \\
\hline Electronic mails & $0.35(4.68 * * *)$ \\
\hline Instant Messages & $0.16(2.07 * *)$ \\
\hline Computerized Maintenance Management Systems (CMMS) & $0.46(6.91 * * *)$ \\
\hline Coefficient of Determination $\left(\mathrm{R}^{2}\right)$ & \\
\hline Electronic mails & 0.35 \\
\hline Instant Messages & 0.15 \\
\hline Computerized Maintenance Management Systems (CMMS) & 0.46 \\
\hline $\mathrm{F}^{2}$ Coefficient & \\
\hline Electronic mails & 0.20 \\
\hline Instant Messages & 0.05 \\
\hline Computerized Maintenance Management Systems (CMMS) & 0.37 \\
\hline$Q^{2}$ & 0.234 \\
\hline
\end{tabular}

According to the results indicates in table 2, it reveals that electronic mails has a positive and statistically significant relationship with employees' job satisfaction $(\beta=0.35, t=4.68, p$ $<0.001)$ and there is a positive relationship between instant messaging and employees' job satisfaction $(\beta=0.16, t=2.07, p$
$<0.01)$. The results indicate that the relationship is in the expected direction and the relationship is statistically significant. The relationship between CMMS and employees' job satisfaction $(\beta=$ $0.46, t=6.91, p<0.001)$ is also positive and statistically significant.

Table 3: Confirmatory Factor Analysis of Constructs

\begin{tabular}{|l|l|l|}
\hline \multicolumn{1}{|c|}{ Item } & \multicolumn{1}{|c|}{$\begin{array}{c}\text { Standardized Factor } \\
\text { Loadings } \\
\text { (t- Value) }\end{array}$} & $\begin{array}{c}\text { Composite } \\
\text { Reliability } \\
\text { /AVE }\end{array}$ \\
\hline Electronic Mails & & $\mathbf{0 . 8 6 5 / 0 6 8 2}$ \\
\hline $\begin{array}{l}\text { The replies to my email messages are } \\
\text { immediate and within satisfied speed }\end{array}$ & $0.822(22.56)$ & \\
\hline $\begin{array}{l}\text { It is easy to express what I want to } \\
\text { communicate through emails }\end{array}$ & $0.786(14.57)$ & \\
\hline Since email communication is mostly & $0.866(33.02)$ & \\
\hline
\end{tabular}




\begin{tabular}{|c|c|c|}
\hline \multirow{2}{*}{$\begin{array}{l}\text { used in my work place it is easy to } \\
\text { work } \\
\text { Instant Messages }\end{array}$} & & \\
\hline & & $0.873 / 0.762$ \\
\hline $\begin{array}{l}\text { The approvals and decision making } \\
\text { more quick because of instant } \\
\text { messaging }\end{array}$ & $0.866(5.16)$ & \\
\hline $\begin{array}{l}\text { The communication within the work } \\
\text { place has increased because of instant } \\
\text { messaging }\end{array}$ & $0.879(6.77)$ & \\
\hline $\begin{array}{ll}\text { Computerized } & \text { Maintenance } \\
\text { Management System } & \\
\end{array}$ & & $0.913 / 0.677$ \\
\hline $\begin{array}{l}\text { The speed of procurement, attending } \\
\text { maintenance work has increased after } \\
\text { introducing CMMS }\end{array}$ & $0.829(25.38)$ & \\
\hline $\begin{array}{l}\text { There is a user friendly interface in } \\
\text { CMMS therefore I am satisfied work } \\
\text { with CMMS }\end{array}$ & $0.874(27.98)$ & \\
\hline $\begin{array}{l}\text { Functioning and accessibility of the } \\
\text { system is always in good condition as I } \\
\text { expect }\end{array}$ & $0.814(17.33)$ & \\
\hline $\begin{array}{l}\text { CMMS facilitates improved } \\
\text { communication between } \\
\text { maintenance team }\end{array}$ & $0.782(22.07)$ & \\
\hline $\begin{array}{l}\text { The present CMMS system easier since } \\
\text { data and information are easily saved } \\
\text { and can be accessed again when needed }\end{array}$ & $0.810(17.76)$ & \\
\hline Job Satisfaction & & $0.912 / 0.512$ \\
\hline $\begin{array}{l}\text { My workplace is well-equipped with } \\
\text { up-to-date equipment such as physical } \\
\text { facilities available for CMC (email, } \\
\text { viber, what's up, web base applications, } \\
\text { etc) }\end{array}$ & $0.703(8.71)$ & \\
\hline $\begin{array}{l}\text { There is no tension at my workplace, } \\
\text { because CMC systems increased } \\
\text { organizational commitment and } \\
\text { reduced work stress }\end{array}$ & $0.824(25.69)$ & \\
\hline $\begin{array}{l}\text { The availability of CMC helps to } \\
\text { develop relationships, so there is } \\
\text { improvement in teamwork at my } \\
\text { workplace with CMC }\end{array}$ & $0.693(11.68)$ & \\
\hline $\begin{array}{l}\text { I can deliver maximum output in par } \\
\text { with my ability using CMC in my } \\
\text { present work }\end{array}$ & $0.741(14.44)$ & \\
\hline $\begin{array}{l}\text { The company policy on CMC system } \\
\text { matches with my interests and } \\
\text { expectations }\end{array}$ & $0.756(15.89)$ & \\
\hline $\begin{array}{l}\text { I recommend CMC system for other } \\
\text { government and private organizations }\end{array}$ & $0.6(7.29)$ & \\
\hline
\end{tabular}




\begin{tabular}{|l|l|l|l|}
\hline $\begin{array}{l}\text { I am pleased to work with CMC it has } \\
\text { less paper work and can store files } \\
\text { electronically }\end{array}$ & $0.632(6.59)$ & \\
\hline $\begin{array}{l}\text { Since I am provided an adequate } \\
\text { training on the CMC systems I am } \\
\text { happy to work with CMC }\end{array}$ & $0.688(10.67)$ & \\
\hline $\begin{array}{l}\text { I am happy to work with CMC because } \\
\text { it delivers the service what I expected }\end{array}$ & $0.797(17.58)$ & \\
\hline $\begin{array}{l}\text { I feel more committed to the } \\
\text { organization because CMC System } \\
\text { allows us to be better informed and } \\
\text { increases information sharing }\end{array}$ & $0.707(11.67)$ & \\
\hline
\end{tabular}

Source: Survey Data (2021)

Confirmatory factor analysis is carrying out on the data to verify the reliability of each measurement scale of variables (Forza, 2002). Standardized factor loadings and outer loading factors of each item and the composite reliability and AVE value of each construct is presented in table 3 . According to the provided guidelines of Bagozzi, Yi, \& Phillips, (1991) the composite reliability of various dimensions is higher than 0.7 and Average Variance Extracted (AVE) is higher than 0.5 is accepted as significant levels. According to Hair, Black, Babin, \& Anderson, (2007) generally larger loadings are the stronger and more reliable the measurement model. The factor loadings of the latent variables are high and statistically significant. According to the results of CFA, this confirms that the indicator variables and their respective underlying constructs are acceptable. The composite reliability values of the study constructs also reveal that the measurement model is reliable.

\section{DISCUSSION}

The main aim of this research is to examine how computer-mediated communication (CMC) systems such as e-mails, IMs, CMMS impact on job satisfaction of employees in Ceylon Electricity Board. The results of the study confirmed a positive and significant impact of electronic mails on the job satisfaction of employees. This finding is in line with the findings of Bob \& Sooknanan, (2014); and Urquhart, Bommelje, \& Schmid, (2002). Moreover, based on the findings of Bob \& Sooknanan, (2014), it is evident that the majority of employees felt that email usage had increased productivity and efficiency in the workplace. Based on Mukahi, Nakamura, \& Not, (2003) email usage is highly important for employees as well as for the performance of the organization. Further, he says that those organizations managing CMC well can gain CMC effects such as increase employee job satisfaction. Also, the result of the study reveals that positive and 
significant impact is found between instant messaging (IM) and job satisfaction. Many of the studies (Chang \& Wan-Zheng, 2014) suggest that IM impact to the employees' job satisfaction. Further, they suggest that the management team of an organization should try to construct a new organizational culture of using IM for communication and problemsolving. Also as a support for these findings, Mahatanankoon, (2010) expresses that instant messaging leads to creativity and influence to increase job satisfaction. As claims of Iskandar, Arham, \& Shohaime, (2017) there is a significant relationship between the uses of instant messaging with performance. Instant messaging is one of the more prominent computer-mediated communications which can boost an instant reaction, similar to face to face communication. $\mathrm{Ou}, \mathrm{Sia}, \&$ Hui, (2013) and Cameron \& Webster, (2005) described instant messaging allows employees to communicate in real-time and shows those who are online and currently available to receive messages.

According to the findings of the research two dimensions of electronic mails and CMMS have a positive significant impact on job satisfaction. Since CMMS is implemented only in the Transmission division of CEB, these findings will help higher management to step forward for CMMS implementation in other divisions of the CEB also. As well as these results show that investing in CMMS implementation in the organization is worth it. Therefore managers can pay more attention to developing facilities for electronic mailing and CMMS without any hesitation. Rastegari \& Mobin, (2016) says that electronic communication between offices in an organization improve with CMMS because they can send work assignments to maintenance workforce through mobile devices and so they can operate more efficiently in the field, for timely completion of required maintenance and repairs. So these findings help managers to decide whether they can extend their communications tools of CMMS to increase job satisfaction more.

\subsection{Managerial Implications}

Quaresma, da Silva, \& Marreiros, (2013) empirically studied the use of e-mail in an organizational context, using a sample of the Portuguese population with an active e-mail account assigned by the employer. The results show that most users have what is considered appropriate behavior and show a positive significant impact on job satisfaction. Therefore it consists of previous studies this study also positively related to empirical study. Therefore according to these findings, the managers should consider solutions for enabling better management of e-mail by its employees by paying more attention to email security. The 
responding speed, easiness of expressing ideas and work easiness in electronic mails are more important in achieving a higher level of job satisfaction. As well as the managers can understand by these findings there the user-friendly interface, good access condition, save and reaccess data and making good communication among the team in CMMS are more important in achieving a higher level of job satisfaction.

On the other hand, the results show that there is a positive and significant impact of instant messaging on job satisfaction. Therefore managers should have to pay their more and more attention to improve instant messaging as one of the communication media in an organization. Some IM applications can use push technology to provide real-time text, which transmits messages character by character, as they are composed. More advanced instant messaging can add file transfer, clickable hyperlinks, Voice over IP, or video chat (Lee, 2011). Therefore such findings imply managerial efforts should be paid to facilitate the good IM application than present to improve the employee's job satisfaction. Cho, Trier, \& Kim, (2005) identified that IM as a double-edged sword. That means IM usage has both positive and negative impacts on employees job satisfaction and performance. Therefore managers have a huge responsibility to identify these negative impacts and get decisions to eliminate them. However, Cho, Trier, \& Kim, (2005) further states that IM can usefully increase other $\mathrm{CMC}$ tools and create an effective and comprehensive $\mathrm{CMC}$ environment in the workplace, therefore, it leads to better work performance of employees. So academics can do further study to find a way to use IM more effectively and comprehensively in the workplace in future.

On the other hand, the study conducted by Iskandar, Arham, \& Shohaime, (2017) one of the public service departments in Malaysia with 132 respondents found that there is a significant relationship between the use of instant messaging and social network with performance. Instant messaging is one of the more prominent computermediated communications which can boost an instant reaction, similar to face to face communication. Ou, Sia, \& Hui, (2013) and Cameron \& Webster, (2005) described instant messaging allows employees to communicate in real-time and shows those who are online and currently available to receive messages. Therefore there should be a proper mechanism to increase instant messaging usage effectively in the public sector in Sri Lanka somewhat advance than the present.

\subsection{Limitations and Future Research}

Executive grade engineers and medium level technical service 
grade employees at transmission division were the key respondents in this study. However, the other employee categories and other divisions of the CEB could have a different response to the study. The sample size was limited to 100 respondents and this too could hinder the generalization of the findings. In this research considered only three CMC dimensions which influence job satisfaction. But there are more CMC dimensions used as organizational communication present. In this study, I selected a reputed leading company in the public sector. But the employees in another public sector organization or private sector organization could have responded differently. Therefore it is important to consider more CMC dimensions in private sector organizations as well in future studies. In this study, only examined the positive effects of $\mathrm{CMC}$ in the workplace. Future research on comparing the advantages and disadvantages of using these CMC and addressing their impacts on individual performance can enhance the entire study. The research was limited to the internal organizational communication of CMC. In future studies, it can be considered external organizational communication in CMC with customer satisfaction or it can study how CMC system impact on the revenue collection of the organization.

\section{REFERENCES}

Anton, C., (2012) McLuhan, Formal cause, and the Future of Technological Mediation. Review of Communication, 12(04), pp. 276-289.DOI: $10.1080 / 15358593.2012 .6$ 87115

Attar, G. A., \& Sweis, R. J. (2010) The Relationship between Information Technology Adoption and Job Satisfaction in Contracting Companies in Jordan. Journal of Information Technology in Construction (ITcon), 15, pp.44-63.

http://www.itcon.org/2010 13 .

Bagozzi, R. P., Yi, Y., \& Phillips, L. W. (1991) Assessing Construct Validity in Organizational Research. Administrative Science Quarterly. pp. 421-458. DOI: $10.2307 / 2393203$

Balouch, R., \& Hassan, F. (2014) Determinants of Job Satisfaction and its Impact on Employee Performance and Turnover Intentions. International Journal of Learning \& Development. pp. 120-140.

DOI:10.5296/ ijld.v4i2.6094

Bälter, O. (1998) Electronic Mail in a Working Context. Nada, Royal Institute of Technology, Sweden: Interaction and Presentation Laboratory (IPLab). 
Beal, V. (2019) Email - electronic mail. Webopedia.

Belle, J. P., Hall, N., Riekert, E., \& Muganda, N. (2007) Exploring the Impact of Computer-mediated Communication on Interpersonal Relationships: A Tentative Model Using Characteristics and Behavioural Outcomes. Alternation,14 (1).

Bob, K. \& Sooknanan, P. (2014) The Impact of ComputerMediated. Advances in Journalism and Communication, 02, pp. 45-50.DOI:

10.4236/ajc. 2014.22005

Bordi, L., Heikkilä, K., \& Okkonen, J. (2014). Digital Work Environment And Employees' Satisfaction With Customer Work.

Brief, A. P., \& Weiss, H. M. (2002). Organizational Behavior: Affect in the Workplace.

ResearchGate, 53, 279307.

DOI: 10.1146/annurev.psych.53 .100901 .135156

Cameron, A. F. \& Webster, J., (2005). Unintended consequences of emerging communication technologies: Instant Messaging in the workplace. Computers in Human Behavior, 21(1), pp.85-103.DOI:

10.1016/j.chb.2003.12.001

Carmines, E. G., \& Zeller, R. A. (1979). Reliability and
Validity Assessment (Vol. 17). Thousand Oaks, CA: Sage. doi: https://dx.DOI.org/10.413 5/9781412985642

Chang, H.-J., \& Wan-Zheng, I. (2014). Instant Messaging Usage and Interruptions in the Workplace. International Journal of Knowledge Content Development \& Technology, 4(2), 25-47

Chauhan, S. P. \& Singh, D. . S., (2016). Study of Computerized

Maintenance Management System (CMMS) and Computer-Aided Maintenance Planning (CAMP) In Production System. International Journal of Scientific \& Engineering Research, 7(12), Pp. 315-318.

Cho, H.-K., Trier, M. and Kim, E. (2005) The use of instant messaging in working relationship development: A case study, Journal of Computer-Mediated Communication, 10 (4).

Cohen, S. (1988) Psychosocial Models of the Role of Social Support in the Etiology of Physical Disease. Health Psychology, 7, 269-297.

Daft, R. L., \& Lengel, R. H. (1986). Organizational Information Requirement, Media Richness and Structural Determinants. Management Science, 32, 554-571. 
Dahanayake, C. (2015).

Discursive-Linguistic

Practices and the Construction of Identity in the Sri Lankan SMS, Social Affairs: A Journal for the Social Sciences, $1(2), 15-32$.

Day, A., Scott, N. \& Kelloway, K., (2010). Information and Communication Technology Implications for Job Stress and Employee Well-being. Research in Occupational Stress and Well Being, 8, pp. 317-350.

Deal, J. J. (2007). Retiring the generation GAP. San Francisco: JosseyBass/Wiley.

December, J. (1997). Notes on defining of computermediated communication. Retrieved February 25, 2012, from http://www.december.com /cmc/mag/1997/jan/decem ber.html

DeSanctis, G. And Poole M.S. (1994) Capturing the Complexity in Advanced Technology Use: Adaptive Structuration Theory. Organization Science, 5(2), 121-147.

Dhir, S. (2018). The Changing Nature of Work, Leadership and Organizational Culture in Future Ready

Organizations. Claremont: Claremont McKenna College.

Epure, D. T., Ionescu, A., \& Nancu, D.. (2013). The
Impact of Communication in Job Satisfaction: an Empirical Investigation within Romanian Companies. Galati: Fascicle I. Economics and Applied Informatics.

Fish, F.E. (1990) Wing Design and Scaling of Flying Fish With Regard to Flight Performance. Journal of Zoology, 221 (3), pp. 391 403.

Fornell, C., and Larcker, D. F. (1981). Evaluating Structural Equation Models with Unobservable Variables and Measurement Error. Journal of Marketing Research, (18:1), pp. 3950.

Forza, C. (2002) Survey Research in Operations

Management: A Process-Based

Perspective. International Journal of Operations \& Production Management, 22 (2), pp. 152-194.

Fulk, J., Schmitz, J., \& Steinfield, C. W. (1990). A Social Influence Model of Technology Use. In J. Fulk \& C. Steinfield (Eds.), Organizations and Communication Technology, pp. 117-140. Newbury Park, CA: Sage.

Giri, V. N., \& Kumar, P. (2010). Assessing the Impact of Organizational Communication on Job Satisfaction and Job Performance. National 
Academy of Psychology
(NAOP) India.

Gopal A, Bostrom, R.P. \& Chin, W.M. (1993) Applying Adaptive Structuration Theory to Investigate the Process of Group Support System Use. Journal of Management Information Systems 9(3), 45-69.

Gush, J. (1999). The Use of Computer-Mediated Communication in the Industrial Placement Year. Emeraldinsight, 41 (2), 63-72.

Hair, J. F., Black, W. C., Babin, B. J. \& Anderson, R. E., (2007). Multivariate Data Analysis. Seventh ed. s.l.:Alaeddine Bagga.

Herzberg, F. (1968). One More Time: How Do You Motivate Employees?. Harvard Business Review. 46 (1): 53-62.

Higgins, L.R., Brautigam, D.P. and Mobley, R.K. (1995), Maintenance Engineering Handbook. 5th ed., McGraw-Hill Inc., New York, NY

Iskandar, A. I., Arham, A. F., \& Shohaime, N. (2017). The Use of Social Media, EMail and Instant Messaging as the Predictors of an Employee's Work Performance. Journal of Academia UiTM Negeri Sembilan, 5, 127-136.

Jacobs, M. A., Yuo, W., \& Chavez, R. (January 2016). The Effect of
Internal Communication and Employee Satisfaction on Supply Chain Integration. ScienceGate, 171(1), 60-70.

Jayalal, S., \& Balasuriya, U. C. (2015). Impact of Social Network Usage on the Job Performance of IT Professionals in Sri Lanka. Kelaniya: ResearchGate.

Kim, J. (2002). Interpersonal Interaction in Computer -Mediated Communication $(C M C)$ : Exploratory Qualitative Research based on Critical Review of the Existing Theories, Proceedings from the Annual Meeting of the International Communication Association, San Diego, California, pp. 1-26.

Koschmann, M. A., (2012). Developing a Communicative Theory of the Nonprofit.

Management

Communication

Quarterly, 26(1), pp. 139146.

Kumar, P. M. (2002). Job satisfaction among permanent and contractual information technology workers. Temple University: Unpublished manuscript.

Larson, G. W. (2011). Instant Messaging. Encyclopedia Britannica.

Lau, K. (2014). ComputerMediated

Communication: Fresno: 


California
University.
Lee, J., Park, D. and Han, I.
(2011), The Different
Effects of Online
Consumer Reviews on
Consumers $\quad$ Purchase
Intentions Depending on
Trust in Online Shopping
Malls: An Advertising
Perspective. $\quad$ Internet
Research, 21 (2), pp. 187-
206.
https://DOI.org/10.1108/1
0662241111123766
Eocke, A. (1976). The nature

Locke, E. A. (1976). The nature and Causes of Job Satisfaction. Handbook of Industrial and Organisational Psychology.

Mahatanankoon, P. (2010). Exploring the Impact of Instant Messaging on Job Satisfaction and Creativity. International Conference on Information Resources (pp. 1-10). CONF-IRM 2010 Proceedings.

Maslow, AH (1954), Motivation and Personality, Harper, New York.

Mertena, F. \& Gloorb, P., (2009). Too Much E-Mail Decreases Job Satisfaction. Georgia, USA., ScienceDirect.

Metz, J. M., (1992). ComputerMediated

Communication:Perceptio $n$ of a New Context, Chicago II: Paper presented at the Speech Communication Association.
Mukahi, T., Nakamura, M., \& Not, R. D. (2003). An Empirical Study on impacts of ComputerMediated Communication Management on Job Satisfaction. Adelaide, South Australia: 7th Pacific Asia Conference on Information Systems,.

Murasugi, K \& Miki, S (1990), Double dual systems of work motivation: an empirical research on the Multi-Motivation Theory in work organization (part 1). Journal of Japan Industrial Management Association, 41 (3), pp. 178-184.

Okwudili, O. M. (2012). Determinant of Effective Job Satisfaction in Public Sector Organization. University Of Nigeria: Department Of Management Faculty Of Business Administration.

Ou, C. X., Sia, C. L., \& Hui, C. K. (2013). Computermediated Communication and Social Networking Tools at Work. Emeraldinsight.

Palme, J. (2000). A Personal History of CMC. Honorary Publication.

Paraskeva, W., Eriksson, Y., Johansson, G. \& Peter, A. (2019) Visual Representations for Communication in Geographically

Distributed New Product Development Projects. Journal of Engineering 
Design, 30, pp. 8-9, 385-

403 , DOI:

$10.1080 / 09544828.2019 .1$

661362

Quaresma, R. F., da Silva, S. P., \& Marreiros, C. G. (2013). E-Mail Usage Practices In An Organizational Context: A Study With Portuguese Workers. Journal of Information Systems and Technology Management, 10 (1), pp. 05-20.

Rastegari, A., \& Mobin, M. (2016). Maintenance Decision Making, Supported By Computerized

Maintenance Management System. Tucson, AZ, USA: The 2016 Reliability and Maintainability Symposium (RAMS $®)$.

Rouse, M. (2008). Unified Technology

Communications Basis. Tech Target.

Rowley, J. (1999). ComputerMediated Communication - is it Good for Organizations. Ormskirk: Industrial and Commercial Training.

Saleem, S., Majeed, S., Aziz, T., \& Usman, M. (February 2013). Determinants of Job Satisfaction among Employees of Banking Industry at Bahawalpur. Journal of Emerging Issues in Economics, Finance and Banking (JEIEFB), 1(2), 150-162.
Samarawickrama, P. (2017). Factors that motivate to use Computer-Mediated Communication (CMC) on Faculty Research Productivity in Sri Lankan. Nugegoda: Knowledge Organization in Academic Libraries.

Simpson, J. (2002). ComputerMediated Communication. ETL Journal.

Smith, W. P., \& Tabak, F. (2009). Monitoring Employee Emails: Is There Any Room for Privacy? ResearchGate.

Stasser, G, (1992). Pooling of Unshared Information during Group Discussion. InS. Worchell, W. Wood, \& J.A. Simpson (eds.), Group processes and productivity (pp.48-67). Newbury Park, CA: Sage

Stefan, H. (2008) Asynchronous \& Synchronous ELearning. Educause Quarterly, 3, $51-55$.

Tu, C. H. (2002). The Impacts of Text-based CMC on Online Social Presence. The Journal of Interactive Online Learning, 1, 124.vog

Urquhart, S., Bommelje, R., \& Schmid, W. (Spring 2002). The Impact of Computer-Mediated Communication on the Workplace. The Florida Communication Journal, 30, 12-24.

Waldeck, J. H., Seibold, D. R., \& Flanagin, A. J. (2004). Organizational 
Gunawardana T.S.L.W., Wayamba Journal of Management 12 (1)

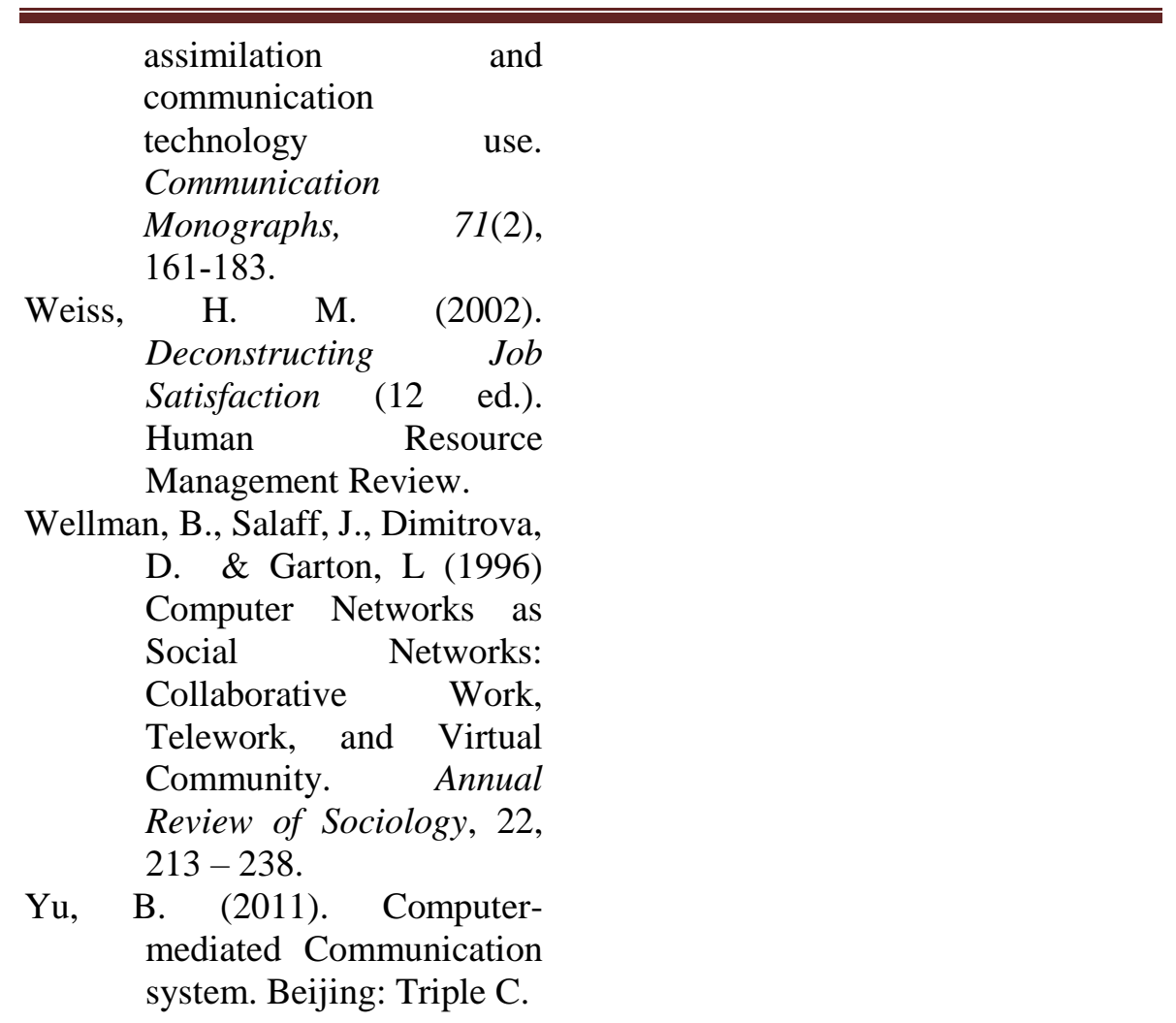

